\section{GLOBALIZACIÓN Y DESNACIONALIZACIÓN EN LA NOVELA PORTUGUESA ACTUAL} NOVELAPORTUGUESA ACTUAL

\author{
M. a Jesús Fernández García \\ Universidad de Extremadura \\ mjesusfg@unex.es
}

\section{GLOBALISATION AND DENATIONALISATION IN THE PORTUGUESE NOVEL TODAY}

Cómo citar este artículo/Citation: Fernández García, M. J. (2014). "Globalización y desnacionalización en la novela portuguesa actual". Arbor, 190 (766): a119. doi: http://dx.doi.org/10.3989/ arbor.2014.766n2011

Recibido: 11 septiembre 2012. Aceptado: 15 julio 2013.

RESUMEN: La literatura portuguesa ha estado a lo largo de su historia especialmente atenta a la construcción de la imagen identitaria de Portugal. Esta preocupación, visible en todos los planos de la vida social, no solo en la producción de los discursos culturales, se ve confrontada al menos desde las dos últimas décadas con el empuje del proceso globalizador, fuerza homogeneizadora que transforma el perfil de las sociedades contemporáneas. El discurso literario acompaña este proceso, lo alimenta y forma parte de él, como tratamos de ver a partir de algunas novelas de reciente publicación en Portugal, abiertas a la simbolización de nuevos paisajes y conflictos que se alejan de la representación en exclusividad del espacio portugués y del debate identitario nacional.

PALABRAS CLAVE: globalización; literatura posnacional; narrativa portuguesa actual; identidad.
Copyright: (C) 2014 CSIC. Este es un artículo de acceso abierto distribuido bajo los términos de la licencia Creative Commons Attribution-Non Commercial (by-nc) Spain 3.0.

ABSTRACT: Throughout its history, Portuguese literature has paid special attention to the construction of the country's national self-image. In recent decades this concern, which is highly visible in all aspects of social life, has been confronted by the push of globalisation, a homogenising force that is changing the profile of contemporary societies. Literary discourse accompanies this process, feeds it and is part of it. This can be seen in some of the recently published novels in Portugal, which are open to the symbolisation of new landscapes and conflicts that depart from the exclusive representation of a Portuguese space and debate on national identity.

KEYWORDS: globalisation; post-national literature; contemporary Portuguese narrative; identity. 


\section{GLOBALIZACIÓN Y LITERATURA}

Mundialización y globalización son términos que, aunque acuñados con anterioridad ${ }^{1}$, han pasado $a$ acomodarse entre las nociones de uso cotidiano de la mayoría de la población mundial en las últimas dos décadas del siglo $\mathrm{XX}$, dando nombre a lo que probablemente debemos considerar un nuevo momento histórico: la era global o la segunda modernidad (Beck, 1998, 26). Los estudios dedicados a la explicación de este proceso transformador y conformador de las sociedades contemporáneas constituyen hoy toda una línea de investigación en continuo crecimiento, con reflexiones que provienen sobre todo del ámbito de las ciencias sociológicas ${ }^{2}$, económicas y políticas. La expansión de un mismo modelo económico, basado en la economía de mercado y en el consumo privado, y la difusión de las comunicaciones, tanto físicas como virtuales, a partir de la aparición de Internet que habilitó la conectividad entre individuos a escala mundial, definen en primera instancia un fenómeno que alberga cambios que se extienden y afectan también a otros planos de la vida social: desde el político, presentando a las democracias como modelos transferibles a cualquier rincón del planeta, hasta el jurídico, haciendo de los derechos humanos un código de aceptación general y promoviendo la constitución de tribunales internacionales que pretenden velar por su cumplimiento. No podemos olvidar otros ámbitos como el educativo, en que se reflexiona sobre la expansión del conocimiento y se impone la noción del ciudadano global, o el cultural, donde la imagen de la aldea global representa un espacio en el que las culturas locales se funden y/o son asimiladas por otras hasta crearse una hipercultura universal sin centro ni referencia ${ }^{3}$. La propagación de un orden cultural transnacional ha estimulado en las últimas décadas las reacciones contra la uniformización y las problemáticas de las identidades minoritarias o minorizadas han tomado nuevo impulso (Lipovetsky \& Serroy, 2010, 23), sobre todo desde el momento en que la lógica del mercado mundial afecta al ámbito de la cultura donde determinadas minorías no tienen "recursos políticos" (Lucas, 2003, 37) para intervenir en el juego de influencias.

Es evidente a la luz de toda la bibliografía sobre este tema que no hay una única interpretación o definición de la globalización, ni unanimidad respecto a su cronología y a los acontecimientos que la impulsaron, si bien el desmoronamiento del bloque comunista soviético y la caída del muro de Berlín en 1989, como acontecimiento simbólico, son los momentos que mayor acuerdo suscitan. También son diversas y muy matizadas las posturas respecto a su valoración, que puede ser positiva, entendida como proceso que puede extender la idea de progreso y justicia social por todo el mundo, o negativa, enjuiciada como peligroso proceso de homogeneización en todos los planos. La opinión que subraya las consecuencias negativas de la globalización argumenta sobre el carácter perjudicial de la imposición de un mercado único, donde las empresas multinacionales operan imponiendo sus intereses económicos, con el apoyo de instituciones internacionales como el FMI, la OMC o el Banco Mundial, auténticos agentes de la globalización económica (Stiglitz, 2009), dejando a los estados nacionales un estrechísimo margen de actuación, condescendientes con las dinámicas neoliberales o "impotentes para contrariar lógicas económicas e políticas supra-estatales" (Silva, 2006, 144), como se ha visto en la crisis financiera de los últimos años. Sin lugar a dudas, lo económico se sitúa en el centro mismo del conjunto de transformaciones que la globalización ha traído a la vida de los ciudadanos de todo el planeta, de modo que otros cambios son a veces sentidos como menores o epifenómenos (Castany, 2007, 21).

Aunque denostada por unos y defendida por otros, de lo que no cabe duda es de que es el momento en el que estamos inmersos y que singulariza nuestro tiempo respecto a los precedentes al poner en escena nuevos conflictos generales y también privados, en una doble dimensión que es a la vez económica y cultural. Nunca como antes de esta era global una cantidad semejante de ciudadanos vio sus prácticas sociales y culturales confrontadas con otras, por contacto directo o a través de la información accesible en tiempo real por múltiples medios (TV, internet, telefonia), entrando necesariamente en una dinámica de transformación que alcanza igualmente a los modos de vida y a las representaciones simbólicas.

Coinciden los autores que han reflexionado sobre este nuevo tiempo en la relación de causa-efecto entre el proceso de globalización y la crisis del estadonación (Habermas, 1994; Beck, 1998, 34; Dehesa, 2000, 110), debilitado este por la aparición de entidades supra-estatales e infra-estatales (Silva, 2006) que coexisten con él y con una sociedad mundial no estatal (Fernandes, 2006, 178-179). Todo ello ha obligado a re-conceptualizar las ideas de comunidad, nación y ciudadanía (Anderson, 1993; Bhabha, 1997; Kriesi, 2001). Desde esta perspectiva la globalización se presenta como un proceso de "desnacionalización", que trastoca la experiencia histórica de la nación tal y 
como se entiende desde su formulación a finales del XVIII y durante el siglo XIX:

Asimismo, el actual proceso de globalización también puede ser concebido como un proceso de "desnacionalización", un proceso que conduce a la disolución de fronteras de los estados nación o a aquello que Ruggie (Ruggie 1993) ha dado en llamar "desempaquetar el territorio". (Kriesi, 2001, 222)

Así, pues, la debilidad del espacio nacional y de sus fronteras para fijar a los individuos a un territorio y constituir sociedades estatales y la fluidez de los intercambios en todos los ámbitos del quehacer humano han provocado la necesaria revisión del concepto de "identidad nacional", cuestionada por la aparición de "espacios sociales transnacionales" (Beck, 1998, $49,99)$ y por la afirmación de identidades de diversa naturaleza (sexual, religiosa, etc.). En sí mismo el carácter fluido y cambiante de la identidad, producto de continuas negociaciones e hibridaciones y construida "de múltiples maneras a través de discursos, prácticas y posiciones diferentes, a menudo cruzados y antagónicos" (Hall, 2003, 17), cuestiona la visión monolítica y estable de lo nacional y de su poder unificador vigente en otras épocas. El debate sobre las identidades nacionales sigue abierto en una época como la nuestra en que "todas las sociedades tienen la identidad malherida", según Amin Maalouf (apud Castany, 2007, 11), y evoluciona siguiendo procesos desiguales, entre el dogmatismo y el escepticismo, si bien en la compleja era global las tensiones se ejercen sobre todo entre el polo de lo global y el de lo local, sobredimensionado precisamente por el empuje globalizador. Sin embargo, el ciudadano de finales del siglo $X X$ y principios del XXI no parece dispuesto a "renunciar a una doble querencia de unión local y vagabundaje global que lo lleva a simultanear ese doble vínculo de fidelidades" (Bouzada, 2006, 164).

Todos los fenómenos con que habitualmente se caracteriza la globalización (la consolidación de una economía de mercado por prácticamente todo el planeta, la expansión de las comunicaciones y transportes, la mundialización de los mercados, también de los culturales, la amenaza de peligros globales como los cambios en el clima, las pandemias, etc.) han promovido la formación de "una comunidad imaginada mundial" (Castany, 2007, 186), de individuos con preocupaciones semejantes, que se superpone a la comunidad imaginada nacional de la que hablaba Benedict Anderson en su obra, ya clásica, Comunidades Imaginadas (1993). En suma, asistimos a un cúmulo de transformaciones a las que los discursos culturales, y entre ellos el literario, no son ajenos, muy al contrario, participan "metabolizando" los cambios en forma de nuevos temas, técnicas y símbolos y, a la vez, contribuyen argumentando en este debate con su propia interpretación de lo humano y sus conflictos.

La relación entre globalización y literatura puede encararse desde distintos frentes, pero sin duda uno de los aspectos en que se hace más evidente la transformación del sistema literario por causa de la mundialización es el de la aparición de una instancia de gran poder e influencia: la de un lector implícito de alcance planetario ${ }^{4}$, que tiene acceso a la obra literaria en espacios tan diversos como la librería, el supermercado, el aeropuerto o internet, traducida a varios idiomas y distribuida por grupos editoriales trans-nacionales. Su alcance, ampliado por los medios de difusión en ondas cada vez más amplias, impondría sobre los textos una especie de "traducción cultural", es decir, "que todos los escritores que pretenden ser leídos a nivel mundial realicen toda una serie de adaptaciones que hagan sus obras inteligibles, racional y sentimentalmente, para la mayoría de los lectores potenciales, sea cual sea su lugar de procedencia" (Castany, 2007, 195-196). Para algunos críticos, en la literatura de la era global se puede distinguir entre la producción literaria que simplemente persigue una adaptación al mercado y para ello tiene en cuenta sus demandas, sin cuestionar la homogeneización cultural que ello pueda comportar, y aquella que pretende un discurso simbólico que refleje auténticos conflictos culturales del presente. Se trata de una distinción controvertida que defiende la existencia de una influencia negativa y otra positiva de la mundialización sobre la literatura y sobre el modo de escribir de los autores contemporáneos. No vamos a avanzar por este frente por tratarse de una cuestión compleja que enlaza con otras distinciones afines (literatura de masas y literatura culta) y que afecta a la literatura como actividad no solo artística sino económica en que además del texto hay que tener presente la extensión de la recepción (a capas sociales más humildes), las estrategias de mercado, la política editorial de traducciones, etc.

Si bien la literatura, su estudio y difusión, ha contribuido históricamente, junto a otros discursos culturales, a la creación de un sentimiento identitario nacional (Anderson, 1993, 46 y 200), es evidente que ese papel se ha visto radicalmente limitado en las sociedades contemporáneas, desempeñado ahora por otras actividades, como el deporte, y otros agentes, como los medios de comunicación. Sin embargo, el modelo nacional está profundamente arraigado como base 
sobre la que construimos nuestro conocimiento de la realidad y entendemos el funcionamiento político de nuestras sociedades (Castany, 2007, 54). No es pues de extrañar que en la literatura actual encontremos continuamente las huellas de lo nacional y, al mismo tiempo, los trazos de su transformación. La designación de literatura posnacional, en consonancia con la aparición de identidades posnacionales (Habermas, 1994) o el post-Estado nacional (Beck, 1998), ha sido empleada para referirse a una tendencia en la creación literaria, especialmente para la narrativa de ficción, en que se advierten nuevas perspectivas y actitudes respecto a la representación de las sociedades contemporáneas: “(...) la novela posnacional tiende a dar cuenta no tanto de una sociedad nacional como de una sociedad mundial. Sus estrategias narrativas y estilísticas así como sus temas y símbolos ya no contarán la historia íntima de las naciones, sino la del mundo." (Castany, 2007, 171)

En otras palabras, identificar una novela como posnacional supone reconocer que ni la visión del mundo representado ni el público al que se destina vienen definidos por el concepto de nación y sus límites tradicionales. Este componente posnacional ha ido ganando presencia en la literatura contemporánea, también en la escrita en Portugal como trataremos de ver. Sin embargo, no podemos olvidar que la perspectiva nacional y la posnacional conviven en cualquier sistema literario, estableciendo entre ellas una relación dialéctica, que reproduce en gran medida la tensión entre lo local y lo global a la que nos referíamos anteriormente y que está moviendo a la redefinición de lo nacional (Castany, 2007, 167). Incluso en la producción de un mismo autor pueden encontrarse obras en que se escoge como objeto de representación la sociedad nacional actual, mientras que en otras esa elección es menos perfilada o simplemente no se da. En cualquier caso, la tensión entre una y otra perspectiva es inevitable si pensamos que las naciones actuales del ámbito occidental son hoy esencialmente multiculturales y la gestión de esta diversidad está en el centro de los conflictos identitarios más relevantes en nuestras sociedades contemporáneas, tanto a nivel colectivo como individual.

Como advierte Bernat Castany $(2007,167)$, al hablar de narrativa posnacional no se puede pensar en un género o corriente homogénea, sino en la presencia de ciertos elementos temáticos y formales asumidos por autores que pretenden construir un universo discursivo más amplio que el de los límites puramente nacionales. A identificar algunos de estos procedimientos en la novelística portuguesa reciente dedicaremos parte de este trabajo, a fin de mostrar cómo se está produciendo el paso de una cosmovisión únicamente nacional hacia una perspectiva que quiere explicar los conflictos de una sociedad de alcance mundial (Castany, 2007, 171), interconectada y tejida a partir de interdependencias sentidas con mayor consciencia que en otras épocas ${ }^{5}$ y al mismo tiempo en latitudes distantes ${ }^{6}$.

\section{GLOBALIZACIÓN Y LITERATURA PORTUGUESA}

Estas reflexiones que están de total actualidad en la apreciación y explicación de la literatura de las últimas tres décadas a nivel mundial tienen especial interés llevadas al terreno de un sistema literario como el portugués, fuertemente nacional tanto en lo que se refiere a la creación artística como al medio académico y crítico que la estudia divulga y traduce. A pesar de este intenso ingrediente nacional, en alguna de la narrativa recientemente publicada en Portugal pueden apreciarse opciones que podemos interpretar como una alternativa a la reflexión identitaria nacional, primordial y casi hegemónica en el discurso literario portugués del siglo $\mathrm{XX}$, con algunas excepciones. Encuadrables en la descripción de literatura posnacional ${ }^{7}$, los títulos a los que nos referiremos parecen sintonizar con preocupaciones vitales (y también estéticas) que, por encima de las fronteras nacionales, vinculan a escritores y lectores de diferentes ámbitos lingüísticos y culturales como ciudadanos del contexto histórico actual que hemos denominado era global o segunda modernidad.

Las aproximaciones a esta cuestión relativas a la literatura portuguesa actual son aún escasas. El escritor y crítico Miguel Real se ha referido a la "internacionalización" de la literatura portuguesa de las últimas dos décadas, advirtiendo en el fenómeno una doble vertiente: por un lado, atañe a la ampliación de los mercados, principalmente europeo y brasileño, al abrigo del éxito internacional de las novelas de José Saramago y António Lobo Antunes; y por otro, se aprecia una internacionalización interna, en que el espacio, los personajes y los conflictos pierden sus referentes estricta y exclusivamente portugueses para dar entrada a protagonistas de procedencia diversa, enfrentados a conflictos vitales que podrían ser los mismos de cualquier individuo de un país occidental o primermundista.

Probablemente esta desfiguración de los perfiles portugueses de la realidad representada a favor de unas coordenadas más universales explique en parte, 
y solo parcialmente, cómo el horizonte de recepción se ha abierto para la narrativa portuguesa contemporánea interesando a un público más amplio, a un lector que podemos considerar global ${ }^{8}$, volviendo rentable su traducción a otras lenguas.

Sin embargo, desenfocar la realidad portuguesa hasta desterritorializarla no es la única vía transitada por la narrativa más reciente. Otro tipo de elecciones puede sugerir una desnacionalización más ideológica que territorial, pues manteniendo un contexto espacial y temporal portugués, tematizan conflictos que pueden ser leídos como comunes a la experiencia contemporánea de lo urbano como micro-universo donde se gestan conflictos semejantes en cualquier latitud del planeta. Así, en su estudio sobre la narrativa portuguesa aparecida durante los años 90, Miguel Real se refiere a una tendencia entre los escritores de fin de siglo a la que denomina "realismo urbano total", definida por la "ausencia de uma ideia unificadora do País" y por la experiencia marcante de la vida en la ciudad", "a nova cidade europeia de Portugal, produtora de uma nova mentalidade cosmopolita, semelhante à mentalidade dos habitantes das grandes cidades europeias" (Real, 2001, 112-113).

Esta nueva generación surgida en la última década del siglo XX presenta una actitud literaria de desapego por las preocupaciones nacionales e de interés por las cuestiones que inquietan al ser humano (en particular, a un yo desesperanzado) en cuanto que ciudadano de grandes urbes, manifestando además una actitud anti-intelectualista hacia la literatura y anti-nacionalista ante la lengua portuguesa, que en ocasiones se mezcla con otras extranjeras. En suma, según Miguel Real, los escritores del "realismo urbano total" reflejan una nueva fase de europeización de Portugal y "um genuíno espírito urbano ou cosmopolita" que los vincula, en gran parte, a los autores de la Generación de Orpheu (Real, 2001, 121). Así para este crítico portugués, son novelas totalmente desnacionalizadas las de Gonçalo M. Tavares y con rasgos de desnacionalización ideológica las de Jacinto Lucas Pires, Rui Zink, Pedro Paixão, Inês Pedrosa, Valter Hugo Mãe, Pedro Mexia o Patrícia Portela, entre otros.

En el panorama novelístico portugués de finales del siglo XX y principios del XXI, el "realismo urbano total" se entremezcla con otras tendencias mucho más apegadas a la representación de Portugal como entidad nacional. Como ocurre en otros sistemas literarios (Zavala, 2008), también en el portugués puede hablarse de un abanico que se abre desde la novelística urbana y cosmopolita, transnacionali- zada, abierta a un lector global, en ocasiones más dependiente del mercado, hasta una narrativa resistente a dichas fuerzas de cambio, interesada por la contextualización nacional de los relatos y ajena a los circuitos de circulación y venta más allá de las fronteras nacionales. Entre una y otra, existen sin duda numerosos estadios intermedios ${ }^{10}$, por lo que apenas podemos pretender una breve presentación de algunos autores y textos que, en nuestra opinión, representan una perspectiva posnacional respecto a la realidad representada literariamente y referirnos a algunas de las opciones narrativas con que se materializa esta apuesta por una cosmovisión alargada de lo humano y su simbolización.

\section{CUÁNDO, CÓMO Y QUIÉN}

Como muy bien analizó Eduardo Lourenço en su $O$ Labirinto da Saudade (1978), obra que marcó un hito en la reflexión sobre la imagen de Portugal y su configuración a través del discurso literario de distintas épocas, la reflexión sobre lo propio o autogénese ha presidido la creación artística en la cultura portuguesa, con especial intensidad en momentos como finales del siglo XIX. El discurso literario contribuyó, junto a otros discursos culturales y sociales, a la formación de una "hiperidentidade" de Portugal, a veces irreal y otras trágica:

(...) a Espanha tem problemas de autodefinição nacional, dada a célebre invertebralidade diagnosticada por Ortega. O nosso caso é outro: tivemos sempre uma vértebra supranumerária, vivemos sempre acima das nossas posses, mas sem problemas de identidade nacional propriamente ditos. (Lourenço, 1978, 18)

La literatura portuguesa ha sido mayoritariamente nacional, preocupada en plasmar y explicar una cosmovisión casi exclusivamente portuguesa de la realidad y de la historia, y en ocasiones nacionalista ${ }^{11}$. A poco que se indague, resulta evidente que Portugal ha sido tema literario de primer orden, si bien ha habido épocas en que esta presencia se aprecia más intensa, mientras que en otras intenta abrirse camino una perspectiva cosmopolita del arte, y que ambas han convivido sin aparente contradicción. Entrados en el siglo XX, uno de estos momentos de intensa literatura nacional se da después de la Revolución de los Claveles, momento en que, acompañando los cambios que se producen en todos los ámbitos de la vida social, también se aprecia en la ficción literaria una ola de revisionismo de la imagen nacional. Desde finales de los 70, pero sobre todo a lo largo de los 80 y gran parte de los 90, se va produciendo ese aparecer de 
una literatura que reflexiona sobre Portugal ${ }^{12}$, su pasado dictatorial inmediato y el presente en transformación ${ }^{13}$. Recuperándose de un tiempo de censura previa y asfixia intelectual, la narrativa de finales del siglo XX acoge la reflexión sobre temas que durante décadas estuvieron prohibidos: la guerra colonial, la emigración portuguesa, la situación de la mujer, etc. El horizonte de interlocución de estas novelas es el de la sociedad portuguesa que se habla a sí misma a través de su literatura.

La intensidad y frecuencia con que se realiza este ejercicio de autorreferencialidad en el discurso literario portugués de los años 80 , en busca de un autoconocimiento primordial, provoca que se alcen algunas voces de queja y de cansancio ${ }^{14}$, como en la advertencia que la escritora Luísa Costa Gomes hace al lector en su obra O Pequeño Mundo (1988):

Leitor! Este livro não fala do 25 de Abril. Não se refere ao 11 de Marco e está-se nas tintas para o 25 de Novembro. Pior, não menciona em lugar nenhum a guerra em África. Não reflecte sobre a nossa identidade cultural como povo, o nosso futuro como nação, o nosso lugar na comunidade europeia. Suportará o leitor um livro assim? Duvido. Foi à sombra do benefício dessa dúvida que o escrevi e agora o dou a publicar.

La huella de la globalización en la narrativa portuguesa, o mejor sería decir la asunción de una perspectiva abiertamente mundial y por lo tanto posnacional, se verifica en la elección de un universo de discurso que no coincide con las coordenadas espaciales, temporales o culturales que identificarían Portugal como estado-nación. Esta apuesta se plasma tempranamente en la obra de uno de sus principales escritores, José Saramago. A pesar de que la representación de la sociedad portuguesa y de su historia colectiva es la base de gran parte de la ficción saramagiana (Memorial do Convento, Levantado do Chão, O Ano da Morte de Ricardo Reis, A Jangada de Pedra, História do Cerco de Lisboa), sin embargo, a partir de O Evangelho segundo Jesus Cristo (1991) se opera un cambio en la elección de la sociedad que ha de servir como referente en novelas posteriores como $O$ Ensaio sobre a Cegueira (1995), A Caverna (2000), Ensaio sobre a Lucidez (2004) o Intermitências da Morte (2005). Los estudios sobre la narrativa de Saramago advierten esta transición, "um certo desenraizamento em favor de um universalismo, de uma globalização" (Berrini, $1998,11)$, distinguiendo entre una primera etapa, en que la realidad portuguesa es materia para la ficción literaria, y una segunda en que Portugal desaparece como telón de fondo sustituido por un no-lugar (Carreira, 2001), con personajes poco identificados en cuanto a su procedencia nacional, que existen en una especie de "temporalidad mundial compartida" (Casany, 2007, 231). Aunque en A Jangada de Pedra (1986) plasmara su desacuerdo con la entrada de españoles y portugueses en la Unión Europea, será sobre todo en esta segunda fase de su producción en la que Saramago pretenda trasladar literariamente un sentimiento de malestar cultural, criticando desde la ficción esta "época hipermoderna de gran desorientación" (Lipovetsky \& Serroy, 2010, 28) y esta nueva forma de totalitarismo que es la globalización económica, evidenciando en cada narrativa el caos hacia el que el capitalismo global conduce al hombre. Sus personajes son miembros de sociedades educadas en el hiperconsumismo que ha anulado su capacidad de crítica, hipnotizados por una determinada noción de progreso y de desarrollo tecnológico. Sin embargo, son capaces aún de reaccionar, como en Ensaio sobre a Lucidez, y de recuperar la capacidad de protestar sintiéndose descreídos de un sistema político, la democracia formal, que únicamente atiende a los intereses de la clase política.

¿Por qué Saramago imprimió un giro tan radical a su obra? Saramago parece pensar en una "comunidad imaginada mundial" (Castany, 2007, 186) al criticar los efectos de la globalización y el papel de los Estados ante la resolución de determinados conflictos, como ante la epidemia de ceguera, la ausencia de la muerte o las papeletas en blanco en unas elecciones generales, pero al mismo tiempo subraya un aspecto positivo: el de la formación de una ciudadanía que reacciona contra los poderes establecidos, creando pequeñas comunidades de solidaridad. No decimos nada nuevo al señalar que el discurso literario de José Saramago se coloca al lado de las voces que desde distintos ámbitos consideran la democracia real, "associativa, local e directa" (Silva, 2006, 145) como la perjudicada por el proceso globalizador liderado por los poderes financieros y la clase política.

Otro ejemplo paradigmático de lo que podríamos considerar desnacionalización del discurso literario nos lo ofrece la obra narrativa de Gonçalo M. Tavares, apreciado por la crítica portuguesa como auténtico autor revelación de inicios del siglo XXI en una categoría que, sin lugar a dudas, podemos considerar literatura culta. La cosmovisión nacional portuguesa desaparece por completo de las novelas de Tavares que escoge para sus relatos un universo cultural localizable en un país indefinido de la Europa Central (Alemania, Austria, Suiza...), como sugieren los nombres de sus personajes, con los que homenajea a grandes escritores del canon europeo: el señor Brecht, Jose- 
ph Walser, Klaus Klum, etc. En un ambiente urbano de tonalidades grises, en ocasiones bajo la amenaza latente de una guerra, se nos presentan conflictos individuales que tienen que ver con las contradicciones y perversiones que el ser humano alberga, cualquiera que sea el marco espacial, temporal y cultural en que se desarrolle su existencia. Se trata pues de identidades problemáticas en las que la cuestión nacional no tiene cabida y el lector implícito no se relaciona directamente con una determinada cultura nacional. ${ }^{15}$

Por último, podemos proponer como ejemplo de lo que venimos considerando literatura posnacional algunas de las producciones de escritores que comienzan a publicar a partir del nuevo siglo: Jacinto Lucas Pires, João Tordo, Valter Hugo Mãe, Afonso Cruz, Sandro Junqueira, entre outros. Así, Jacinto Lucas Pires plasma en su novela Perfeitos Milagres (2007) una cosmovisión desnacionalizada respecto a Portugal, perspectiva que se evidencia en la mayor parte de las elecciones narrativas realizadas: desde la ambientación en Nueva York, paisaje mitificado y auténtico icono de la era global, hasta los personajes principales, entre los que se encuentra un típico producto de la cultura global, la estrella de rock Trick Watso, cuya fama alcanza a todos los rincones del planeta, pero que sin embargo necesita reconstruir su propia identidad apagada por el personaje mediático en que se ha convertido. En varios sentidos y planos encontramos en esta novela un claro ejercicio de cosmopolitización de la realidad, fundamentalmente en la elección de los conflictos de índole personal en el caso del cantante Watso y de Carlos Abroso, periodista portugués y locutor de la TV1 destacado en Nueva York, quien está preparando un libro sobre gente común neoyorquina, "histórias anónimas que nunca ninguém regista mas que definem o fundo essencial de uma cidade" (Pires, 2007, 281).

En las novelas de João Tordo, los personajes principales (y habitualmente narradores en primera persona) o bien no aparecen adscritos a una cultura concreta o son personajes híbridos culturalmente, a caballo entre la identidad portuguesa y cualquier otra. Se establece así una relación entre el espacio portugués y los espacios internacionales que pueden ser Inglaterra (O Livro dos Homens sem Luz, 2004), Estados Unidos (Hotel Memória, 2007 y parte de As Três Vidas, 2009), Italia (O Bom Inverno, 2010), Alemania (Anatómia dos Mártires, 2011) o Canadá (O Ano Sabático, 2012). El componente cosmopolita se intensifica con personajes que hablan idiomas, estudian literatura extranjera y son competentes en otras culturas como la anglosajona. En suma, João Tordo escoge protagonistas que se aproximan a la idea de individuos biculturales, enfrentados sobre todo a problemas de identidad personal donde el ingrediente nacional no entra en juego.

\section{RECURSOS PARA LA DESNACIONALIZACIÓN EN LA NARRATIVA}

Vamos a referirnos brevemente a algunas de estas opciones estilísticas que nos parecen más significativas, conscientes de que existen otros procedimientos con que se podría justificar y ejemplificar la asunción de una perspectiva posnacional en la literatura portuguesa actual ${ }^{16}$. Aunque en su mayoría no pueden considerarse marcas exclusivas de la narrativa desnacionalizada, en conjunto nos permiten una lectura que ejemplifica "el giro posnacional" (Castany, 2007, 320) de la literatura escrita en Portugal y, por añadidura, su sintonía con una tendencia que se aprecia en otros ámbitos culturales y sistemas literarios.

\subsection{La elección del espacio}

La elección del espacio donde se desarrollan algunas de las novelas publicadas en las últimas décadas en Portugal nos permiten hablar de desterritorialización de los relatos, realizada en varios sentidos: bien porque el espacio pierde su perfil portugués y se difumina en un paisaje urbano, donde escasean los hitos espaciales reconocibles como pertenecientes al estado-nación que es Portugal; sencillamente porque el relato se ambienta en un país extranjero o bien porque en el desarrollo de la acción se produce un desplazamiento desde Portugal a otros países.

La primera de estas vías de desterritorialización de las coordenadas espaciales es la que lleva a cabo José Saramago al sustituir el universo de referencias espaciales reconocidamente portuguesas por el no-lugar donde se ambientan algunas de sus novelas, muy especialmente Ensaio sobre a Cegueira, Ensaio sobre a Lucidez o As Intermitências da Morte. Como ningún otro autor portugués, Saramago traslada a sus novelas la idea de una comunidad social que habita un espacio sin las marcas de identificación espacio-temporal habituales (Carreira, 2007, 201), dando al lector el poder de colocar su particular toponimia. Interesado sobre todo por plasmar su reflexión ética y política, profundamente crítica con ciertos aspectos de la globalización, Saramago pensaba en un "lector implícito mundial" (Castany, 2007, 186 y 194) y para alcanzarlo opta por una configuración cronotópica sin perfiles nacionales, por lo tanto sin centralidad geopolítica ni esencialidad histórica. 
El espacio por excelencia en la novela posnacional es la ciudad global. Como afirman los sociólogos de la globalización, cuando el estado-nación pierde su centralidad como categoría para el desarrollo de las relaciones sociales y políticas, este debilitamiento parcial refuerza la posición de nuevos espacios políticos subnacionales o infra-estatales, como la ciudad y las regiones, o unidades espaciales supranacionales, como los mercados virtuales, en que no entran en juego las fronteras nacionales y geográficas tradicionales (Sassen, 2007, 246) o supra-estatal como, por ejemplo, la Unión Europea y sus instituciones (Silva, 2006, 132). La ciudad, sin ser un espacio novedoso para la literatura (basta recordar la importancia de la ciudad para los movimientos de vanguardia de inicio del siglo XX), sí es una demarcación nueva en cuanto que espacio global o de la globalidad que contiene en sí misma todas las micro-estructuras que componen la diversidad: nuevas clases globales, desde las élites transnacionales hasta la clase global de los marginados (sin abrigo, inmigrantes o bandas violentas), que habitan fuera de control las periferias de la ciudad posmoderna o las ciudades miseria (Davis, 2008). Cada ciudad será, pues, reproducción del gran puzle mundial y de todos sus elementos, imposible de identificar con un referente real en el caso de la ciudad por donde deambulan los ciegos en la novela de José Saramago Ensaio sobre a Cegueira a la búsqueda de la casa de cada uno, metáfora de la identidad individual perdida (Carreira, 2002). Dentro de la ciudad, espacios como el centro comercial de A Caverna se alzan como símbolo de un nuevo orden en las relaciones de poder que exige el ajuste de los individuos a las leyes del consumo.

En la literatura posnacional, los nombres de las ciudades son en cierta medida intercambiables: Lisboa, Londres o Nueva York. Será Lisboa en la novela de Jacinto Lucas Pires Do Sol (2004), donde la multiplicidad de voces narradoras son el traslado literario del barullo polifónico que puebla cualquier ciudad, individuos que se acumulan ante un semáforo y son anónimos unos para los otros, aunque las acciones de uno pueden desencadenar consecuencias en la vida de otros en un efecto mariposa imparable. La ciudad global alberga consciencias perturbadas (como las del político prometedor pero asesino y acosador o la del violador, en esta obra) y alimenta la incomunicación entre sus moradores. Sin embargo, es Nueva York la ciudad por donde deambulan los personajes en otra de las novelas de este mismo autor, Perfeitos Milagres (2007) a la que ya nos hemos referido. También se ambienta en la gran urbe norteamericana Hotel Memória de João
Tordo, mientras que O Livro dos Homens sem Luz se desarrolla en Londres. En todos los casos, la ciudad existe como un laberinto que acompaña la confusión interior de personajes que han de resolver el enigma de su identidad individual, por tanto, también en la literatura la ciudad "posmoderna" es en esencia una "enciclopedia de recorridos dispares"17.

Por su parte Gonçalo M. Tavares ha creado el Bairro al que se trasladan a vivir vecinos tan ilustres como los señores Valéry, Calvino, Breton, Walser, Eliot, etc. Este nuevo espacio ficcional, que se extiende con la publicación de cada nuevo libro (una decena hasta el momento), como un barrio se alarga con la llegada de nuevos inquilinos, se superpone a cualquier espacio identitario nacional, más próximo a la idea de una arcadia contemporánea e internacional. ${ }^{18}$

La elección de un espacio extranjero para la localización de los relatos se ha convertido en una opción frecuente, reiteradamente buscada por la narrativa más reciente, como muestran títulos como $A$ Boneca de Koloschka (2010) de Afonso Cruz o A Desumanização (2013) de Valter Hugo Mãe.

Por último, el espacio puede "desnacionalizarse" a través del viaje, lo que supone la co-existencia de diversos espacios y culturas. El ser humano de la globalización es con mucha frecuencia un individuo en permanente movilidad y por medio del viaje se alcanza una especie de hibridación entre lo nacional y lo internacional. El viaje en sí mismo es un tópico que comporta el encuentro con la cultura-otra y estimula la reflexión sobre los rasgos identitarios vinculados a la noción de lo nacional. Sin embargo, en la novela de la globalización el viaje pierde en gran parte esta función. Viajar o desplazarse de un país a otro es un hábito usual y hasta banal para determinadas clases sociales, que no siempre provoca meditaciones sobre la existencia de fronteras que separan estados y usos culturales. En un mundo también globalizado por los transportes, salir de Portugal es un ejercicio de cosmopolitismo que subraya la pertenencia de los personajes a una comunidad mundial donde los flujos de viajeros son corrientes. Podemos, sin embargo, concederle algún significado a la dirección de los viajes, con frecuencia se sale desde Portugal al encuentro de nuevos espacios: hacia Brasil, en A Eternidade $e$ o Desejo (2007) de Inês Pedrosa, o Japón en Portokyoto de Pedro Paixão (2001), Israel y Holanda en No Silêncio de Deus (2008) de Patricia Reis o Canadá en O Ano Sabático (2012) de João Tordo. La dirección que toman los viajeros repetidamente es el mundo anglosajón, con preferencia por los EUA (Os Surfistas, 
2001, de Rui Zink; A Cidade Depois, 2001, de Pedro Paixão; Táxi, 2001, de José Couto Nogueira; As Três Vidas, 2005, de João Tordo).

\subsection{Personajes sin nombre y sin patria}

Uno de los primeros elementos que identifica al personaje, vinculándolo a una cultura y con frecuencia a un espacio nacional, es su nombre propio. Sin embargo, cuando no se pretende esta relación y, al contrario, quiere evitarse cualquier identificación nacional, el nombre puede llegar incluso a desaparecer, como sucede en Ensaio sobre a Cegueira de José Saramago, ejemplo paradigmático de este recurso, donde los personajes son presentados por algún rasgo de su físico, de su profesión o de sus relaciones de parentesco, como "la mujer del médico". Al desaparecer el nombre se borra cualquier indicio de identidad nacional para subrayar otros rasgos que tienen que ver con la "complejidad identitaria" (Castany, 2007, 219) y, en el caso de la novela citada, con su condición anónima de seres humanos inmersos en la lucha cotidiana por la supervivencia emocional y vital. El recurso a la ausencia de nombre propio es especialmente significativo en la narrativa de José Saramago en la que es frecuente encontrar reflexiones sobre el valor del nombre y explicaciones sobre algunos de ellos (Berrini, 1998, 144-146).

Por otro lado, no son completamente extraños en algunas novelas de reciente publicación los personajes principales de nacionalidad no portuguesa como el personaje narrador en Hotel Memória de João Tordo, los personajes de Perfeitos Milagres de Jacinto Lucas Pires, a los que se les supone un origen estadounidense, o los de A Desumanizaçao de Valter Hugo Mae. Del mismo modo la nacionalidad no es relevante en el caso de los personajes creados por Gonçalo M. Tavares. En ocasiones, estos personajes extranjeros coexisten con algún otro de nacionalidad portuguesa como sucede en Perfeitos Milagres, donde aparece el periodista portugués y locutor de la TV1 destacado en Nueva York, Carlos Abroso, o en Anatomia dos Mártires de João Tordo. No se trata, sin embargo, de la figura del emigrante, de tan largo tratamiento en la literatura portuguesa, sino de personajes que encajan en un puzle de individuos de sociedades desarrolladas y primermundistas posibles en cualquier parte del planeta. Como veremos, para estos personajes no-portugueses el conflicto central es el de su identidad individual en un mundo de referencias globales (marcas comerciales, música y cine, tecnología, etc.) y en ocasiones no se especifica su pertenencia a un espacio nacional concreto.

\subsection{Los conflictos}

En la base de los relatos que estamos considerando crece siempre un conflicto identitario, de modo que las identidades problemáticas caracterizan la narrativa de corte posnacional, ya sean colectividades cuestionadas por adversidades de alcance global o identidades individuales que tratan de reconstruirse en el seno de la compleja sociedad hipercapitalista y multicultural. Además, sea cual sea la raíz del conflicto, la visión uniformizadora del discurso nacional no ofrece respuestas satisfactorias a la problemática de la identidad.

Los conflictos colectivos, de carácter político y social, son privilegiados en la narrativa de José Saramago, quien crea la ilusión ficcional del mundo como un todo, donde lo local se convierte en global. Una vez más la epidemia de ceguera (Ensaio sobre a Cegueira) sería el caso paradigmático de esta visión totalizadora de la humanidad y sus problemas, como ya comentamos. De igual forma nos coloca ante la idea de la interconexión con que se desarrolla la existencia humana, contribuyendo a la sensación de que compartimos una temporalidad mundial (Castany, 2007, 231), el telón de fondo elegido por Patricia Reis para su novela Por este Mundo Acima (2011), donde un accidente de alcance mundial ha reducido a escombros las grandes ciudades del planeta, incluida Lisboa, convirtiendo a los supervivientes en bandas de desorientados entre sus ruinas.

Sin embargo, son bastante más tratados los conflictos individuales que tocan a la identidad personal, desprovista de preocupaciones de identificación nacional, pero angustiada por un "sentimiento trágico de la existencia” (Castany, 2007, 219). La incomunicación, fomentada por un progreso deshumanizador, consumista y tecnológico, se alza como auténtica frontera entre los individuos y desestructura fragmentando las identidades individuales. De ahí nacen personajes que "viajan" dentro de la ciudad a la búsqueda de elementos, como los fragmentos de memoria, que les ayuden a recomponerse. El objetivo de ese vagabundeo vital es recuperar el perfil de una identidad propia, deformada por un modo de vida, un global life style (Lucas, 2003,47$)$, que ha conducido, por ejemplo, a Trick Watson, "a super-mega-estrela do novo hiper-mundoglobal" de piel blanca, sin vello ni manchas (Perfeitos Milagres, 120), a convertirse en un individuo escindido entre un yo confuso y la estrella de rock, que se ofrece como modelo planetario ante millones de jóvenes. Pero esta imagen es solo el disfraz que le permite sobrevivir a la invención de sí mismo. 
Aunque el conflicto pueda referirse a personajes portugueses y se enmarque en coordenadas nacionales ofrece una lectura que alcanza al hombre contemporáneo, habitante de las grandes urbes contemporáneas. El malestar cultural que caracteriza a los personajes de Pedro Paixão puede tomarse como ejemplo de ello (Nos teus braços morreríamos, 1998; Amor Portátil, 1999) o la desorientación vital del protagonista de $O$ Verdadeiro Ator de Jacinto Lucas Pires, pero también los conflictos que nacen de la experiencia de la soledad y de la violencia en el medio urbano y que relegan a los individuos a la exclusión social, representados en la narrativa más reciente por personajes que proceden de las zonas oscuras de la sociedad primermundista (O meu Nome é Legião, 2007, de António Lobo Antunes; Coração sem abrigo (2009) de José Jorge Letria).

Al mapa diverso de la exclusión social hay que añadir una nueva forma de desarraigo identitario: el que procede de la inmigración y que viene a poner en evidencia las dificultades en la gestión de la diversidad cultural por parte de las sociedades receptoras de inmigrantes. La presencia del personaje del inmigrante, especialmente la de trabajadores de procedencia eslava $^{19}$, se ha ido haciendo más visible en la literatura portuguesa reciente, pasando de un lugar secundario en el dibujo del cuadro social al primer lugar de la escena en novelas como Myra (2009) de Maria Velho da Costa. En esta obra, acompañamos al personaje principal, la joven Myra, de procedencia rusa, en su deambular por un mundo portugués heterogéneo, fundamentalmente adverso y cruel aunque también feliz y mágico en algunos momentos. Pese a todo, Myra no experimenta una auténtica acogida y no consigue aplacar el sueño de regresar a su país de origen, que es, por encima de todo, el país de los afectos. El conflicto de la identidad individual y la dificultad para la comunicación y el encuentro personal con los otros, unidos a su condición de extranjera, empujan a la protagonista hacia un destino de marginalización ${ }^{20}$.

La intensidad con que la emigración ha transformado el perfil de las sociedades primermundistas ha puesto de relieve los problemas y dificultades del mestizaje y la hibridación. No es extraño, pues, que veamos la figura del extranjero inmigrante en Portugal incorporada al puzle social que encontramos en novelas como Sopa (2004) de Filomena Marona Beja, Náufragos do Mar da Palha (2007) de João Medina y O Apocalipse dos Trabalhadores (2008) de Valter Hugo Mãe ${ }^{21}$. La relación intercultural tiene en esta última novela un matiz esperanzador respecto al futu- ro de las sociedades multiculturales al presentar una relación humanizadora entre una mujer portuguesa y su amante ucraniano. Es esta vía, es decir, la de la literatura que focaliza los espacios para la hibridación, el tercer espacio o el entre-medio a los que se refiere $\mathrm{H}$. Bhabha (2002), donde se juega un interesante debate sobre el multiculturalismo, que la literatura portuguesa, por el momento, solo ha rozado ocasionalmente.

Una obra que merece alguna atención en el marco del diálogo entre lo nacional y lo posnacional es la novela Náufragos do Mar da Palha de João Medina en que encontramos un personaje, el profesor de filosofía Tito, en el que confluyen orígenes ucranianos, judíos, mozambiqueños y portugueses, ampliamente descritos como medio para retratar una identidad ambigua y compleja en sí misma. Tito se reúne todos los sábados por la mañana con un grupo de antiguos alumnos de instituto, que forman una pequeña tertulia en la cafetería Mar da Palha. Allí profiere encendidos discursos en donde problematiza los acontecimientos históricos y el discurso de la identidad nacional portuguesa construida a lo largo de los siglos por la historiografía nacionalista y simplificada en la era global en meras "imágenes de marca". El análisis de la historia patria que lleva a cabo el profesor pretende contrariar las bases ideológicas sobre las que se asienta la idea de Portugal como nación, hasta concluir que "Portugal es un error histórico". Pese a defender la teoría de que todos los individuos son parte de "uma raça universal de co-exiliados" (140), predicando una visión universalista de la humanidad que la propia variedad étnica de los presentes en la cafería ejemplifica, a Tito le inquieta únicamente el futuro del Portugal contemporáneo al que ve mal acoplado en el "contexto globalizante e convivente da União Europeia" (79). Con ironía y desafecto se refiere al mapa europeo en el que falta "agora saber o que é que somos, o que vamos fazer e qual o nosso futuro como pós-nação nesta Europa de pós-nações" (134). De este modo en el pensamiento del antiguo profesor de filosofía confluyen, dando lugar a una profunda paradoja, la explicación del objeto (Portugal y su construcción como estado-nación) y la negación del mismo por medio de una feroz crítica antinacionalista, pero a la vez se muestra en desacuerdo con la deriva posnacional:

Antigamente, este agregado de razões e justificações chamava-se nacionalismo, mas hoje que a União Europeia - e outras formas de globalização multinacional em marcha - se vai construindo, passando do Estado-Nação ao Estado Supra-nacional ou Transnacional ou Pós-Nacional ou Federação de Países, do mesmo modo que um corpo em estado sólido pode 
passar ao gasoso - pois os álibis nacionalistas cheiram a mofo ou, pior! tresandam a carne queimada, a churrascos históricos da mais atroz memória -, que solução devemos adoptar para recomeçar a nossa vida! que Utopia, que projecto, que propósito de recomeço de vida, que sonho, que desejo? (81)

En esta novela de corte ensayístico y filosófico, en que se procede a una auténtica radiografía de la evolución histórica de Portugal desde la óptica demoledora y pesimista del antiguo profesor de filosofía, el espacio de la cafetería, que sirve de punto de encuentro a los participantes de la tertulia y al mismo tiempo es el lugar de trabajo de varios personajes extranjeros, resume el rostro multicultural de la sociedad portuguesa contemporánea, retratada toda ella como una reunión de náufragos, sacudidos por los avatares de la historia colectiva y de cada una de sus trayectorias individuales. Pese a la presencia de estos náufragos procedentes de mares diversos (Paquistán, Mozambique o Ucrania), la obra de João Medina tiene como principal horizonte de lectura para la mayor parte de sus capítulos un lector portugués, como lo es el fiel auditorio del profesor de filosofía.

\section{LA CARA POSNACIONAL DE LA NARRATIVA PORTUGUESA}

Partíamos al inicio de este trabajo de la constatación de que el discurso literario, su estudio y su divulgación han tenido un papel fundamental en la construcción, o "imaginación" en la terminología de Benedict Anderson (1993), de Portugal como nación al menos desde finales del siglo XVIII. La crítica literaria y los historiadores de la literatura portuguesa han puesto de realce esta circunstancia, incluso para periodos anteriores que podrían considerarse prenacionales. Que sigue muy vivo en la cultura portuguesa actual el debate identitario nacional, tan cuidadosamente alimentado por creadores, historiadores y filósofos portugueses a lo largo de los siglos, lo prueban ensayos de reflexión de reciente publicación como Portugal Hoje, O Medo de Existir (2004) de José Gil, A Morte de Portugal (2008) o A Vocação Histórica de Portugal (2012) de Miguel Real, entre otras obras que, siguiendo la estela de Eduardo Lourenço y su Labirinto da Saudade, reflejan la existencia de una intelectualidad preocupada por el proceso de deconstrucción de la identidad nacional portuguesa ante el desafío globalizador ${ }^{22}$. En gran parte, la literatura actual acompaña esta preocupación y ofrece bastantes ejemplos de novelas fuertemente contextualizadas en la realidad portuguesa, en sus "traumas" y en sus momentos fundacionales pasados y presentes, pero incluso cuando esto sucede el discurso literario no puede obviar una nueva configuración de la sociedad portuguesa actual donde, por ejemplo, es de vital importancia la inmigración, fenómeno de globalización por excelencia en el paso del siglo XX al XXI, junto a otros procesos no menos transformadores como la descomposición de la cultura rural a favor de la concentración en el medio urbano.

Esta co-existencia de la literatura nacional y la que hemos denominado posnacional o globalizada es esencialmente compleja. Pese a que las huellas de la transformación son evidentes en las novelas que hemos usado para ilustrarla, no se puede afirmar que ambas perspectivas, la nacional y la posnacional, sean opuestas. En la producción de un mismo autor puede darse una obra encuadrable en una u otra modalidad. Si las coordenadas espaciales en Perfectos Milagres de Jacinto Lucas Pires nos remiten a un contexto urbano, paradigmático para toda la cultura occidental como es el medio norteamericano, en otra novela de este autor, O Verdadeiro Ator (2011), apreciamos un regreso a los referentes espacio-temporales nacionales y a la ficción de asuntos contextualizados en la realidad histórica portuguesa más reciente, incluida la crisis económica. Al contrario, Valter Hugo Mãe pasa de una contextualización vinculada estrechamente a Portugal en novelas como $O$ apocalipse dos trabalhadores y $A$ máquina de fazer espanhóis a un espacio ajeno a las coordenadas nacionales portuguesas en $A$ desumanização (2013), ambientada en Islandia.

En suma, al hablar de literatura posnacional en Portugal hemos pretendido señalar, por un lado, algunas obras que no tienen como único y principal referente el espacio nacional y la sociedad a él ligado: no pretenden hablar de sí mismas y para sí mismas sino que tienen presente un lector implícito que no es "un patriota en formación sino, más bien, en disolución" (Castany, 2007, 194). Estas novelas representan un importante desvío respecto a la constante histórica de predominio de una literatura autorreferencial, que pretendía fundamentalmente explicar y representar la realidad nacional portuguesa. Por otro lado, hemos visto que incluso aquellas obras que parten de un universo portugués incorporan preocupaciones que tienen que ver con la globalización como fenómeno conformador de las nuevas sociedades, ofreciendo una mirada crítica sobre este proceso como agente de los conflictos individuales y colectivos.

Pero si la novela nacional servía a una función conocida de explicación de la propia comunidad nacional, ¿qué papel puede asumir esta literatura que des- 
territorializa la narración? En el caso de la narrativa de José Saramago es evidente que se da un propósito de movilización de la conciencia del lector y se persigue su reacción, aunque esta se limite a despertar su sentido crítico. En esta línea algunos de los últimos títulos de Saramago, como Ensaio sobre a Cegueira, A Caverna o Ensaio sobre a Lucidez, se unen desde el discurso literario a voces de muy diversa procedencia que intentan articular una respuesta crítica a la globalización como "processo de desenraizamento territorial e de destituição político-jurídica" promovido por las corporaciones transnacionales y los mercados financieros, quienes "representam, pela via da mercadorização em regime hegemónico e (quase)monopolístico, o mais profundo e subtil ataque à democracia representativa" (Silva, 2006, 133).

Sin embargo, dejando a un lado la producción de José Saramago y su conocida implicación con causas de naturaleza política, en la mayoría de los casos la movilización de las consciencias no puede ser interpretada como objetivo del texto literario, a pesar de que algunos autores atribuyan un contenido ético-político a la literatura posnacional (Castany, 2007, 205). La descreencia en el poder del discurso artístico para impulsar la acción colectiva en nuestras sociedades tecnológicas y urbanitas puede ilustrarse con un episodio contenido en la novela de Jacinto Lucas Pires, Perfeitos Milagres, a la que ya nos hemos referido repetidas veces. En ella, un grupo de actores se propone despertar las conciencias de los ciudadanos a través de una performance que mezcla teatro con la explosión de unas bombas de corto alcance que al explotar lanzan miles de papelitos al aire con consignas para la reflexión sobre el modo de vivir contemporáneo. El resultado buscado se resuelve en fracaso porque las explosiones no solo no llaman la atención de los viandantes sino que en una de ellas una de las actrices muere.
Puede, no obstante, reconocerse en algunos casos una función catártica cuando es tratada la problemática de la identidad individual presente en la mayoría de los relatos a los que nos hemos referido al mostrar "personajes tan escindidos identitariamente" (Castany, 2007, 222) que buscan espacios de desahogo y desarrollo personal en las sociedades urbanas, tensión que puede muy bien comprender y compartir un lector mundial.

Parece hoy día fuera de toda discusión el hecho de que la literatura ha perdido su papel relevante como discurso cultural que contribuía a la creación y el aliento de la comunidad imaginada que es toda nación. Frente a prácticas que continúan siendo fuertemente nacionales (como, por ejemplo, el discurso deportivo), otras parecen ejercer su fuerza en sentido contrario, desnacionalizando gustos, como el cine, la música y, con frecuencia, la literatura. Se ve con ello, como señalábamos al inicio, que lo nacional y lo posnacional no son momentos cronológicos diferentes, sino fuerzas en constante relación dialéctica (Castany, 2007, 186), que se dan en el sistema literario de una lengua nacional e incluso en un mismo autor. Caminarán juntas visto que la preocupación por la identidad cultural de la nación se reactiva continuamente como reacción al empuje globalizador $y$, en consecuencia, surgen los discursos de carácter nacional y nacionalista (en el ámbito portugués son especialmente visibles en el género ensayístico). Pero al mismo tiempo continuará, sin duda, la reacción posnacional en busca de nuevos paisajes y conflictos para un mensaje literario que sea sentido a la vez como portugués y mundial. Se impone pues habituarnos a esta negociación, que será sin duda fértil, entre lo local y lo global también en la literatura. 
1 La creación del término globalización ha sido atribuido a Marshal Mc Luhan (The Medium Is the Messaje, 1961/1967) y su expansión alcanza al ámbito anglosajón, mientras que en los estudios franceses se prefiere mayoritariamente la designación mundialización. Otros términos se vinculan a estos y se usan en ocasiones como si fueran intercambiables: universalización, transnacionalización, occidentalización, americanización, globalismo, si bien algunos autores proponen distinguirlos (Beck, 1998, 26, 127; Oleza, 2004, 141; Bouzada, 2006, 152 154). En el ámbito más específico de lo cultural surgen nuevos términos para designar una noción en apariencia idéntica aunque matizable según la perspectiva con que se aborde su descripción e implicaciones (Lucas, 2003, 36-37): multiculturalismo, interculturalidad, transculturalidad, homogeneización cultural, hibridación, macdonalización, norteamericanización, sincronización cultural o ecumenismo global. Además el término glocalización, neologismo creado por R. Robertson (Globalization. Londres, 1992), incide especialmente en la relación de interdependencia entre el ámbito de lo local y lo global.

2 La bibliografía sobre este temática supera con creces los márgenes de este trabajo, por lo que recogemos al final únicamente algunos títulos en que hemos apoyado nuestra reflexión: U. Beck, Anthony Giddens, Joseph Stiglitz, GuiIlermo de la Dehesa o Javier de Lucas.

3 Gilles Lipovetsky y Jean Serroy (2010) han acuñado la expresión CulturaMundo para referirse a la época "de expansão assombrosa do universo da comunicação, da informação e da mediatização" (14), en la que el capitalismo "funciona como uma cultura sem fronteiras, uma cultura-mundo" (49).

4 Nunca este lector universal ha tenido tanta consistencia como en el presente, imponiendo una especie de "traducción cultural" a los autores y apoyado por la política de mercado de los grandes grupos editoriales de carácter internacional, con traductores fijos, que promocionan determinados productos convirtiéndolos en éxito de ventas y contribuyen así a crear una especie de modelo literario dominante con géneros privilegiados, como la novela de intriga histórica y la novela policial. Sin olvidar que internet, como canal de difusión, es el medio más determinante en la globalización de la recepción.
5 Bien es verdad que en todas las etapas históricas pueden encontrarse escritores que han insistido en una concepción universal de lo humano y han criticado la artificialidad del sentimiento nacional, defendiendo un territorio "supranacional" para el arte, sin embargo parece ampliamente aceptado que la perspectiva nacional ha dominado el discurso literario, su producción y su estudio, desde hace ya más de dos siglos.

6 El debate sobre las transformaciones que la globalización ha acarreado al campo literario ha sido especialmente intenso en el ámbito latinoamericano. Mientras que para algunos críticos, la globalización supone sin lugar a dudas pérdida de identidad cultural y violenta homogeneización (Zavala, 2008), experiencias como las del grupo MacOndo (Edmundo Paz Soldán, Alberto Fuguet, Sergio Gómez, entre otros) pretenden superar moldes estereotipados como, por ejemplo, el realismo mágico, convertido en "obligatorio" para la literatura hispanoamericana desde que lo desarrollaran los autores del "boom" de los años 60. Frente a este cliché, los autores del grupo MacOndo producen relatos en que el ambiente globalizado, urbano y tecnológico, con la cultura de masas de fondo, están presentes como alternativa a la imagen exclusivamente rural de las sociedades latinoamericanas. El funcionamiento del mundo urbano permite, además, indagar en la degradación de las relaciones personales y el estallido de múltiples conflictos identitarios individuales, sin que los relatos pretendan ser retratos sociales.

7 Reflexión que también se ha iniciado para el cine portugués y su paso a un cine posnacional o "cinema do mundo", como ha visto Tiago Baptista (2011) en algunas producciones portuguesas en donde se produce un "alargamento a franjas da população que até ali, tinham permanecido ausentes de filmes portugueses", en referencia a los inmigrantes. (13)

8 Esta es una cuestión compleja, porque si bien es cierto que los autores en los que apreciamos marcas de abertura a lo global o mundial son al mismo tiempo los más internacionales, como José Saramago, no lo son menos otros en que las marcas no son tan radicales como António Lobo Antunes, a cuya novelística se le puede reconocer un valor universalista, o aquellos instalados en un universo de discurso esencialmente portugués como José Luís
Peixoto y que, sin embargo, están siendo objeto de una recepción internacional muy amplia.

9 Corriente que muy bien podría ponerse en conexión con el "realismo virtual" al que se refieren los escritores hispanoamericanos Alberto Fuguet y Sergio Gómez en la introducción a su antología de cuentos titulada McOndo (Barcelona, Grijalbo-Mondadori, 1996), historias que desinteresadas por la identidad colectiva latinoamericana se centran "en realidades individuales y privadas" y se ambientan en un país "grande, superpoblado y lleno de contaminación, con autopistas, metro, tv-cable y barriadas. En McOndo hay MacDonald's, computadoras Mac y condominios, amén de hoteles cinco estrellas construidos con dinero lavado y malls gigantescos." $(1996,4)$.

10 No entraremos en otros productos que se vinculan igualmente al proceso globalizador como el hiper-desarrollo de ciertas tendencias como la novela de intriga y ficción pseudo-científica, al estilo de un Dan Brown, cuyo máximo exponente en Portugal sería el escritor José Rodrigues dos Santos. Estos géneros que habitualmente se incluyen en la llamada "literatura ligth" o "de aeropuerto" pueden considerarse la plasmación literaria de un modelo cultural dominante. No es este nuestro propósito, pero sin duda habrá que reflexionar sobre las influencias mutuas y la línea fina que separa hoy la literatura culta y la de masas, transición realizada a través de una literatura pseudoculta o ligeramente desintelectualizada, que es sin duda la más apreciada por el gran público. Todos los autores que consideramos pertenecen a lo que podríamos considerar literatura culta y, por distintas vías (traducciones, premios, presencia en historias de la literatura), forman parte de lo que podríamos considerar el canon literario portugués.

11 Distinción entre literatura nacional y nacionalista que, en palabras de Bernat Castany Prado, se sustenta sobre el hecho de que la segunda "no solo tiene como universo de discurso la propia nación sino que, además, busca difundir entre sus lectores este particular modo de concebir el mundo y la identidad. Se trata, pues, de una pedagogía nacionalista, más o menos explícita. Desde este punto de vista toda literatura nacionalista es nacional pero no toda literatura nacional es nacionalista" $(2007,168)$ 
12 Como muy bien ha visto Ana Isabel Briones, en las décadas de 80 y 90, para una gran parte de los más importantes escritores portugueses, el tema literario por excelencia es Portugal "com intenção tanto reflexiva como combativa" (Briones, 1992, 208).

13 Títulos como Lusitânia (1980) de Almeida Faria dentro de su Tretalogia Lusitana, Levantado do Chão (1980) de José Saramago, O Dia dos Prodígios (1980) y A Costa dos Murmúrios (1988) de Lídia Jorge, Viagem de um Pai e de um Filho pelas Ruas da Amargura (1981) de Baptista Bastos, Fado Alexandrino (1983) y As Naus (1988) entre otras novelas de António Lobo Antunes, Alexandra Alpha (1987) de José Cardoso Pires, Missa in Albis (1988) de Maria Velho da Costa - Crónica do Tempo de Isabel Barreno (1991), entre otras.

14 Sin llegar a ser un repudio de la patria, esta es tratada con humor e ironía en obras como Hotel Lusitano (1987) de Rui Zink.

15 Gonçalo M. Tavares concibe un tipo de lector libre de encuadramientos nacionales: "Não devemos ser excessivamente patriotas enquanto leitores. Um leitor é alguém que lê, e tenta ler o meIhor possível, o que mais se aproxima de si, sem nenhum outro critério que não o desejo de ler. Julgo que mais do que uma literatura de um país, se deve falar de literatura numa língua." (Entrevista realizada para Portal da Literatura: www.portaldaliteratura.com/entrevistas.php?id=8 Consultado en Julio 2011).

16 En su estudio Literatura Posnacional (2007), Bernat Castany ensaya una descripción de las características fundamentales de la narrativa que denomina posnacional (175-235): el perspectivismo y la dialogicidad, la construcción de personajes complejos y contradictorios, con problemáticas identitarias o biculturales, la reflexión sobre la identidad colectiva e individual que se resuelve habitualmente en escepticismo, la hibridación y el mestizaje, la construcción de nuevas metáforas y el uso de paradojas, el cruce de lenguajes procedentes del cine o la televisión y el intercambio de recursos propios de otros géneros, la fuerte presencia del presente como tiempo privilegiado de modo que el relato va al encuentro de la narración periodística, la referencia a elementos de la cultura de masas y a las marcas publicitarias, la aparición de toda una imaginería que tiene que ver con la presencia de ordenadores y la comunicación a través de internet o de teléfonos móviles, etc.

17 Entre la ciudad modernista y la posmoderna pueden apreciarse diferencias: "La ciudad deja de dibujarse con la lógica de la planificación estructural modernista para convertirse, como recuerda D. Harvey (1998, p. 332), en una enciclopedia de recorridos dispares, en la que las diferencias étnicas y culturales, los ámbitos heterogéneos, las soluciones particulares, priman sobre el orden y las relaciones de cohesión, sobre aquel concierto de partes y de funciones que, en los orígenes de la Modernidad, los románticos alemanes sustanciaron en la palabra "orgánico". Y esta vasta enciclopedia desagregada que es la ciudad posmoderna se presenta siempre -y no podría ser de otra forma- con una disposición multicultural" (Oleza, 2004, 134).

18 En toda la producción de Gonçalo M. Tavares, también en los libros que componen "O Reino" (Jerusalém, A Máquina de Joseph Walser, Aprender a Rezar na Era da Técnica...), se puede apreciar la elección de un espacio que no se vincula a un referente local concreto, cuyas marcas lo separan de una identificación con Portugal.

19 Durante los años iniciales del siglo XXI Portugal fue receptor de inmigrantes, proceso que se ha invertido con la crisis económica a partir de 2010. Aparecieron en ese tiempo publicadas novelas que incorporaban la figura del inmigrante, con especial presencia de la inmigración eslava. Esta materia ha sido estudiada por Miguel Real: “Imagens de imigrantes eslavos na literatura portuguesa - o caso de A Sopa, de Filomena Marona Beja", conferencia presentada al Congreso internacional Iberian and Slavonic Cultures in Contact and Comparison: Towards Crisis and Prosperity, celebrado en Lisboa en abril de 2007 y por Isabel Morán Cabanas,"Representações de Imigrantes Eslavos na Narrativa Portuguesa dos Últimos Anos (2004-2007): Personagens e Discursos", comunicación presentada a la Conferência Internacional de Intercâmbio Ibero-Eslavo: Intra Muros - Ante Portas, Faculdade de Letras da Universidade de Lisboa- Portugal, 2008. Abordamos la imagen del inmigrante en la narrativa portuguesa actual, en Fernández (2012).

20 Pues su periplo concluye con su encierro en una casa de prostitución, junto a mujeres brasileñas.

21 En las tres novelas aparecen personajes de origen ucraniano.

22 No solo desde el ensayo, también el medio universitario se ha ocupado de esta problemática: Boaventura de Sousa Santos (org.), Globalização: Fatalidade ou Utopia? (Ed. Afrontameno, 2001), dentro de la colección: A Sociedade Portuguesa Perante os Desafios da Globalização. 
Anderson, Benedict (1993): Comunidades Imaginadas. Reflexiones sobre el origen y la difusión del Nacionalismo. México, Fondo de Cultura Económica.

Bhabha, Homi (2002): El lugar de la cultura. Buenos Aires, Ediciones Manantial.

Bhabha, Homi (2003): "El entre-medio de la cultura", en Stuart Hall y Paul du Gay (comps.), Cuestiones de identidad cultural. Buenos Aires, Amorrortu, 94-106.

Batista, Tiago (2011): "Depois do cinema português", Frederico Lopes (org.), Cinema em Português. Covilhã, LabComBooks, pp. 5-20.

Beck, Ulrich (1998): ¿Qué es la globalización? Falacias del globalismo, respuestas a la globalización. Barcelona, Paidós.

Berrini, Beatriz (1998): Ler Saramago: o romance. Lisboa, Caminho.

Bouzada Fernandez, Xan (2006): “Identidad y cultura en la sociedad globalizada: algunas reflexiones a propósito de los nuevos desafíos locales en el ámbito de las políticas culturales", en Manuel Carlos Silva (org.), Nação e Estado. Entre o Global e o Local. Porto, Edições Afrontamento, pp. 151-175.

Briones García, Ana Isabel (1992): "Algumas tendências no romance português mais recente (1987-1990)", Revista de Filología Románica, 9, 207-223.

Carreira, Shirley de Souza Gomes (2001) "O não-lugar da escritura: uma leitura de Ensaio sobre a Cegueira de José Saramago", Sincronia-An E-Journal of Culture Studies. México. (Consultado en www.alfarrábio.di.uminho.pt/vercial/ zips/shirley01.rtf)

Carreira, Shirley de Souza Gomes (2002): "A (des)construção da identidade nos romances de José Saramago (consultado en www.alfarrábio.di.uminho.pt/ vercial/zips/shirley02.rtf

Castany Prado, Bernat (2007), Literatura Posnacional. Murcia, Editum.

Davis, Mike (2008), Planeta de Ciudades Miseria. Madrid, Foca.

Dehesa, Guillermo de la (2000), Comprender la globalización, Madrid, Alianza.

Fernandes, António Teixeira (2006), "A legitimidade na era da mundialização", en Manuel Carlos Silva (org.), Nação e Estado. Entre o Global e o Local. Porto, Edições Afrontamento, pp. 177-186.

Fernández, María Jesús (2013), “Imigrantes na narrativa portuguesa contemporânea", Hispanisme, no 1, pp. 126-147. (En http://www.hispanistes. org/component/content/article/31hispanismes/279-numeros-de-la-revuehispanismes.html)

Giddens, Anthony (2001), Un mundo desbocado: los efectos de la globalización en nuestras vidas. Madrid, Taurus.

Gutiérrez Mouat, Ricardo (2002): “Literatura y globalización: tres novelas postmacondistas", Inti, Revista de Literatura hispánica, 55-56, pp. 3-28.

Habermas, Jürgen (1994), Identidades nacionales y postnacionales. Madrid, Tecnos.

Hall, Stuart \& Gay, Paul du (2003), Cuestiones de identidad cultural. Madrid, Amorrortu.

Kriesi, Hanspeter (2001), "La transformación del espacio político nacional en un mundo globalizado", in Ramón Máiz (coord.), Construcción de Europa, Democracia y Globalización, vol. 1, Santiago de Compostela, Universidad de Santiago de Compostela, pp. 219-237.
Lipovetsky, Gilles y Serroy, Jean (2008), A Cultura-Mundo. Resposta a uma Sociedade Desorientada. Lisboa, Edições 70

Lourenço, Eduardo (1978), O Labirinto da Saudade. Lisboa, Gradiva.

Lucas, Javier de (2003), Globalización e Identidades. Icaria ed.

Maalouf, Amim (2005), El desajuste del mundo: cuando nuestras civilizaciones se agotan. Alianza Editorial.

Oleza, Joan (2004), "Multiculturalismo y globalización: pensando históricamente el presente desde la literatura", Prosopopeya. Revista de crítica contemporánea, no 4, pp. 133-156

Real, Miguel (2001), Geração de 90. Romance e Sociedade no Portugal Contemporâneo. Lisboa, Campo das Letras.

Sassen, Saskia (2007), Una sociología de la globalización. Buenos Aires, Katz.

Silva, Manuel Carlos (2006), "Entre o infra-estatal e o supra-estatal: o EstadoNação e a democracia em perda", Manuel Carlos Silva (org.), Nação e Estado. Entre o Global e o Local. Porto, Edições Afrontamento, pp. 129-149.

Stiglitz, Joseph E. (2009), El malestar en la globalización. Madrid, Santillana (3a edición).

Zavala, Magda (2008), “Globalización y literatura en América Central: escritores y editoriales", en Verner Mackenbach (2008), Intersecciones y transgresiones: propuestas para una historiografía literaria en Centroamérica. Tomo I. Guatemala, F\&G Editores. Consultado en www.lasa.international.pilt.edu/ lasa2001/ZavalaMagda.pdf 